\title{
Net-Space as Civil Society-Space?
}

Matthew Friedman, Fuzzy Logic: Dispatches from the Information Revolution (Montreal: Vehicule Press 1997)

In Fuzzy Logic: Dispatches from the Information Revolution, Matthew Friedman does an excellent job capturing the present as defined by technology and by our ability to shape the direction of its impact on our lives. Particularly refreshing is Friedman's refusal to attempt to map out where advances in technology will ultimately lead us. Technology will continue to permeate our environment, he argues, but change takes place at such a rapid pace that making predictions is, at best, a difficult endeavor.

Fuzzy Logic is full of political metaphors which reveal Friedman's take on the possibilities technology offers not just to techno-philes, but, more importantly, to the Net-surfer who explores cyberspace as both consumer and producer of information. Friedman describes the scene as an "information revolution" in which the possibilities for guerilla warfare are endless. The Internet is a tool that serves the popular as much or more than the techno-corporate state. Fuzzy Logic is primarily about how the masses (loosely defined) use the Internet to serve their own needs and not how the Bill Gates' of the cyberworld use it to enhance their own power. And the domain of the popular is where culture is free and can be appropriated, via technology, for multiple purposes. There is no single force behind technology and, therefore, it cannot be tied together under a Master Name.

Friedman also avoids giving machines a life of their own as is often done in movies like The Terminator. For him, the subject-object split is distinct; the question is whether or not this is true for most? Friedman often attributes his own moderate reading of a world drenched in technology without considering whether others do the same. On this level, his project is aimed at maintaining agency for carbonoids who use technology in their everyday lives to create meaning for themselves. His book is highly informative, but it is also a wakeup call for all of the potential revolutionaries who might use technology to recreate the experimental space of civil society on the Net. Friedman is the voice of Dewey who would attempt to harness technology and the information revolution for the good of the "global community" - another term that, perhaps in an attempt to cast a wider net, is never thoroughly defined.

In chapter one, Friedman takes us on a walk through various technological advances from the typewriter, the telephone, and the steam engine, to the evolution of computers. The book provides a wonderful lens into the practical impact of technology on society. He describes how our economic base has been transformed by the ability to produce and circulate information with inventions such as the printing press and the typewriter - which brought women into the workforce to fill clerical jobs. From the early days of the 
industrial revolution, technology reshaped society and the same continues to happen today. We are becoming more of an information economy where information itself is the product of exchange. Friedman's description of the commodification of information and the abstraction of capital is interesting, but a bit brief. He describes how technology has made speculation in the marketplace more efficient through abstraction, but never carries his ideas much further. The implications, however, are clear. The stock market lets society dream beyond its "real" means. It is an imaginary world where one can flaunt one's simulated wealth. Its velocity is facilitated by machines and today's stock market crashes are little more than a slap in an imaginary face; a crash is an imaginary crisis that does not hurt most of us but supports the "times are tough" chorus around which people mobilize. It signifies a collective loss of faith in a fragile economic system.

At the end of chapter one Friedman once again brings us directly back to the political by raising the question of the revolutionary nature of technology. "Are we destined to remain idle consumers of pre-packaged goods, or are we empowered by the new technology?" The information economy, where information is privately held, accumulated, and controlled as commodity, and the information society, where it is reserved for the common good, are essentially at odds." (33) Although he never defines what the "common good" is and whether we can even talk about it as such, he presents us with an interesting scene where a war is being waged between the people for access to technology and information to use for their own good, and those in positions of power who hoard technology and information for profit. The presentation is a nostalgic and, at best, simplistic picture of forces in society squaring off against one another; one group wants technology for the maximization of profit and the other for more humane reasons. In a world where there will not likely be any more revolutions off-line, perhaps this is how the possibility of a revolution is (re)generated - through mobilizing revolution efforts on-line in order to posit the age-old fight of good against evil. This move points to a mourning for something that was perhaps never adequate to history.

The idea that infomation and technology in the hands of the masses is the great social equalizer is rather optimistic. The gutting of the Left with the fall of Communism results in this sort of desperation and Foucault is our social critic par excellence. Indeed, information is not untainted by the code and therefore it cannot be looked at independent of power/knowledge relays - to do so is utopianism in its most vulgar form.

An information revolution that will greatly alter social and political structures is predicated on the notion that people want the revolution in the first place. The possibility that they are playing with the product information absent any stakes which can be attached to a political project is never really examined by Friedman. The possibility of further democratization via the information revolution is dangled before us without ever engaging the possibility that infor- 
mation is entangled in power/knowledge grids that reproduce state-forms. Issues of access to information hide the notion that machines more effieciently circulate technologies of power that Foucault identified.

Perhaps Friedman points us towards the death of experimental politics in the social by positing its (virtual) existence on the Internet. The (dead) space of civil society off-line is transposed onto Internet space in order to posit interaction "with a community as a whole." (41) Is it the new great space of experimentation? On many levels it is, but to tie that experimentation together under the banner of community as a(ny) whole seems, at best, nostalgic and at worst is a taming of differentiation under the (Leftist) banner of community politics. And if it is social space, we can expect it to mirror many of the same biases and disciplinary mechanisms as off-line social space. Indeed, the Internet offers opportunities for creativity, political expression, micro-resistance, subversive activities, detournemant, etc., but to posit it as a some sort of recreation of a radical civil society is dubious. Friedman is careful to debunk the idea that a single mind can be found on the Internet, but rhetoric like the "global village" and a "global 'groupmind" sound like an attempt by the Left to create the revolution they were robbed of in virtual space. The Net becomes our last chance to recreate the ideal community. "It promises a fundamental redefinition of the local community by infinitely extending personal space beyond the tidy boundaries of the backyard fence." (43) The personal is the political ... and it will not be long before the oppressed of the Net begin to rise as well.

Friedman presents a fascinating description of the various ways technology transforms relations between nation-states. Because of technology, nationstates are not tied as much to territory as a determinant of their resources and power. Technology allows smaller and poorer countries to play at politics on a field that has been substantially leveled. It also challenges the ability of nationstates to represent their power - a computer and a modem might be the newest weapons of choice for terrorists. The problem, Friedman is quick to point out, is that many weaker countries are dependent upon developed countries for the technology with which they can gain leverage politically, militarily, and economically. Technology allows developing countries to modernize at a faster pace, but modernization may still mean a level of dependence upon developed countries.

Friedman continues his analysis by pointing out the fact that the new transnationals in the information economy will be companies like MCI. These telecommunications companies will control access to information by developing countries which will need them to provide the necessary technology to get "hooked-up." In this sense, what the information economy offers these countries is little more than different economies of interest in the game of neo-colonialism. Friedman sums it up nicely:

The tools and infrastructure of the information economy are being 
exported in the name of neoliberalism and the promised freedom may not be so much an equitable access to the global resource of information, but freedom to consume information products. (56)

In an age of pan-capitalism, Friedman is correct to point out that we might expect transnationals to run the global economy. He does not, however, specifically define neoliberalism and whether or not it offers resistance to this scenario. For some, it is little more than liberal fascism marking the death of civil society. For others, it offers the possibility of the revival of a (Marxian) Left. If neoliberals are Clinton Democrats, those mourning the disappearance of the Left have little reason for solace. Many of his solutions to today's problems revolve around the closure of the space of civil society - more police on the streets, mandatory school uniforms, and mandatory drug tests for kids who want a driver's license.

Excitement over the notion that the Net does not let anyone hide might also be tempered with a turn to Foucault. "There's a sense that the government can't hide anything, that the whole world is watching." (89) Rather than transparency being the sign of an empowered people, for Foucault it was the sign of the advancement of a technology of power that brought more people into networks of surveillance and thus normalization and disciplinization. Transparency, then, is a productive power in which we all act as relays of a power that does not disappear once brought into the light but, rather, is further disseminated with greater efficiency. Just as Foucault read the Inquisition in modern psychiatry, so does the Net house the Inquisition in the form of chat rooms, support groups, and the like.

As Friedman emphasizes, there is no one source of Power behind the Net; such structural mapping has been abandoned by most who have at least a familiarity with postmodern approaches to analyzing texts. That does not, however, imply the disappearance of power. Foucault has taught us that power is capillary and transparency is its ultimate mode of circulation. Power is a machinery that no one individual or state apparatus controls. We all are bearers of a technology of power. Disciplinization is brought to the next level ... beyond self-disciplinization to the point where we become the eyes that watch each other. The chat room as support group becomes a confessional where power is exercised over bodies gone astray. Transparency increases and disperses power rather than jamming its codes. This is not to say that resistance and evasion are futile, for power is not always victorious. The Net does offer opportunities for the disempowered to resist and evade. But a dose of Foucault tempers the celebratory tone of a (virtual) recreation of the space of civil society in the supposed "light" of power derailed.

Friedman takes a calm and rational look at racism on the Internet. Although his lumping together of various right-wing groups is deceptive i.e., all militia groups are not alike and they often differ greatly from Christian 
Identity groups and the Montana Freemen - he does not pick up the banner of censorship against these various groups. He is clearly unhappy about the fact that racism is found on the Internet, but using government regulation to counter it will threaten the right we all have to free speech. Friedman also takes up a very nice critique of the paternalism involved in those who are out there to "protect us" from the dangers of the Internet. His unmasking of campaign slogans like "protect the children" as little more than a means to promote political agendas and clamp down on the exercise of free speech is refreshing. Without promoting "indecency" on the Net, Friedman offers an even tempered critique of the fact that the effort by "gatekeepers" to catch up with the regulation of information in cyberspace is motivated first by political gain when it should be approached from a legal perspective.

Friedman locates one of the mechanisms of power the Internet gives to us. There are few editors working the Net determining what should and should not be published. With few exceptions, anyone can publish anything in cyberspace. Indeed, as Friedman suggests, the Net may be more political than voting because it is so unregulated. And regulating expression on the Net is a way of de-politicizing voices on the Net. The voice of "morality" (i.e., protecting the children, etc.) is used to mask the exercise of power over free speech - a typical political ploy that Friedman demystifies nicely. Furthermore, he once again points to the challenge the information revolution - mediated via cyberspace - poses to the state's ability to represent its dominion over space and the activities within it. Attempts by the state to regulate and control information in cyberspace, then, are a (hysterical) move to represent its power in an environment where it may already be dead.

Friedman also offers insight into the challenges brought by changes in our economic base. New skills are necessary for workers in an information economy, yet most are not adequately trained to work in this environment. This is certainly true in America. Vocational training has never been one of its strong points, and Friedman has found more evidence pointing in this direction. An untrained workforce is not unique to the information economy, but the contrast between low and high wages will most likely be greater as more and more industrial and service-based jobs disappear.

Ironically, the tendency for the information economy to result in fewer jobs for people because of increased efficiency in the production of information via computers, may ultimately strengthen the nation-state. As has happened with the loss of industrial jobs to Mexico and Asia, the loss of computer-based information jobs to the same places may result in increased nationalism. After all, the Marxist dream of "workers of the world unite" is dead and buried. Workers tend to rally around the flag when their jobs are lost to areas where production is cheaper. In this sense, that which challenges nation-states because of its chaotic nature and lack of boundaries - the information economy - may also be that which bolsters the nation-state. 
Friedman accurately concludes that technology is no panacea. He is careful to mention that we must decide what it can and cannot do well. We are social animals who desire contact with other humans. Learning, for example, is an endeavor that we can best carry out through interaction with others. He also aptly rejects binaries which posit culture against nature as no longer appropriate to our times. One cannot imagine an area of nature that has avoided the touch of culture in some way (i.e., via acid rain, etc). Most could not, and do not desire to, live the secluded life of the Unabomber. In fact, it is because of technology that we live as well as we do. At the same time, however, it is also prudent to avoid the extreme in the search for redemption - be it from a body that fails us or an environment that is not to our liking through a mad rush towards technology. Indeed, technology is a tool of our environment that can benefit human life but it does not come without its costs and implications for conceptualizing that which is valued in (hegemonic) society.

This is a point that deserves further consideration in Fuzzy Logic. Friedman's approach to technology may be Nietzschean in that it is but one of many tools in his environment, but the hype around integrating technology into the classroom, for example, suggests that others may consider it to be far more. $\mathrm{He}$ does a nice job revealing the weaknesses in neo-Luddite rhetoric, but to assume that all users of technology are as reasonable in their approach toward it is a bit optimistic. We may be living in an age when, for the first time in history, our tools are no longer adapted to us. We must adapt ourselves to them and the fit is often less than comfortable. Friedman is quick to discredit neoLuddites without considering the possibility that there might be some value found in their critique of technology. After all, aren't we all living in a (postmodern) society where distinctions between subject and object are not so readily made? In many ways, perhaps technology has become a fetish for more than the neo-Luddites. It has become the mediator of our relationships with one another. We relate to each other (and distance ourselves from one another) via technology; could we do it any other way? It is via technology - that which is external to us - that some constitute themselves. It offers (the illusion of) redemption, so to speak, from a body that dies and from a hostile environment that seldom meets with our expectations. In many cases, machines are a substitute for one's imagination and for critical thought rather than an enhancement of them.

Certainly not all neo-Luddites, or their counter extreme, the techno-utopians, are as extreme as Friedman paints them. One has to wonder whether he identifies the extremes on two sides of the issue of technology in order to create a reasonable middle-ground that he can occupy. If so, this approach is as reductionist as he accuses the extremes of being in relation to issues of technology, and metonymy is employed for his own ideological reasons. This is the point-counter point approach found so often in the hegemonic media. Issues 


\section{Left History 5.2}

are broken down into minute details and used to represent the "whole debate." A more careful approach would have been to find and appropriate, in as many positions as possible, insights in relation to a technological world and to dispense with what is not useful in analyzing the impact of the information revolution on our lives. By sacrificing the neo-Luddites and the techno-utopians, Friedman creates the appearance that his ground is the only safe and reasonable ground on which to stand. He does, however, nicely challenge arguments revolving around who should and should not have access to technology and information.

Finally, although many Internet users operate in opposition to the technocorporate state - consciously or otherwise - as many (and probably more) do not. The Internet is not a free-zone removed from interpellation into hegemonic ideologies. The Internet is a tool for the circulation of interpellation into both hegemonic and non-hegemonic ideologies. One cannot assume that its "interactive" nature results in critical thought. The Internet may simply mobilize an emotion much like the nightly news does. In fact, it often enhances one's ability to construct a virtual environment of clones who not only look alike but also think alike. Although the Internet offers exciting possibilities for resistance, subversion, and evasion, it is unclear how many people use it for those purposes and the impact they will have on a society where opposition to norms is, at best, difficult to find. In short, I am less convinced than Friedman of the revitalization of civil society on the Internet.

Overall, Fuzzy Logic is a book well worth reading. It is engaging and challenges the reader to reconsider his/her position in relation to technology and the information revolution. Indeed, "The street must make its own use of things." (198) The best application of Friedman's advice may be to, as much as is possible, and with a dose of (Baudrillardean) indifference, appropriate technology as a tool of our environment in order to negotiate and maneuver within that environment.

Tim Seul

Adams State College 